\title{
Endoscopic Keyhole Approach for Intracranial Epidermoid
}

\author{
Pawan K. Verma ${ }^{1} \quad$ Amanjot Singh ${ }^{1} \quad$ Priyadarshi Dikshit $^{1}$ Kuntal Kanti Das ${ }^{1}$ Anant Mehrotra ${ }^{1}$ \\ Sushila Jaiswal ${ }^{2}$ Sanjay Behari ${ }^{1} \quad$ Awadhesh K. Jaiswal $^{1}$ \\ ${ }^{1}$ Department of Neurosurgery, Sanjay Gandhi Postgraduate Institute \\ of Medical Sciences, Lucknow, Uttar Pradesh, India \\ 2 Department of Pathology, Sanjay Gandhi Postgraduate Institute of \\ Medical Sciences, Lucknow, Uttar Pradesh, India \\ Address for correspondence Awadhesh K. Jaiswal, MCh, Department \\ of Neurosurgery, Sanjay Gandhi Postgraduate Institute of Medical \\ Sciences, Raebareli Road, Lucknow, Uttar Pradesh 226014, India \\ (e-mail: jaiswal_dr_2002@yahoo.co.in).
}

J Neurosci Rural Pract 2021;12:614-622.

\section{Abstract \\ Keywords \\ - endoscopic \\ - epidermoid \\ - intracranial \\ - keyhole \\ - minimally invasive techniques \\ - pure \\ - tailored craniotomy}

Objective In contemporary neurosurgical practice, keyhole endoscopic approach has established its role in various neurosurgical pathologies. Intracranial epidermoid is an ideal pathology for endoscopic keyhole approach as epidermoid is well encapsulated, extra-axial, avascular, and easily suckable. The objective of this study is to share our experience of endoscopic keyhole approach for intracranial epidermoids at various locations as a new minimally invasive neurosurgical approach to deal with these lesions. Materials and Methods We conducted a retrospective study on 26 patients who underwent keyhole pure endoscopic excision of intracranial epidermoid between July 2015 and December 2019. Patient's demographics, clinical features, radiological imaging, and postoperative complications were noted. Follow-up outcome of preoperative symptoms and postoperative complications were also analyzed.

Results The mean age of the study population was 30.5 years with a mean follow-up of 30 months. The common presenting features were headache, hearing loss, and trigeminal neuralgic pain. Gross total resection was achieved in $73.1 \%$ cases, while near total resection and subtotal resection were achieved in 19.2 and $7.7 \%$ cases, respectively. In the follow-up, maximal improvement was seen in trigeminal neuralgic pain (83\%) and headache (66.7\%). Major postoperative complications were facial nerve paresis, lower cranial nerve paresis, and transient facial hypoesthesia, most of which improved over time. None of the patients required resurgery till date.

Statistical Analysis Patients' data were analyzed using SPSS software version 23 (Statistical Package for Social Sciences, IBM, Chicago, United States).

Conclusion This study demonstrates that with careful patient selection, endoscopic keyhole excision of epidermoid is a good alternative to conventional microsurgical excision with comparable surgical and functional outcomes. published online September 23, 2021
DOI https://doi.org/ 10.1055/s-0041-1735283. ISSN 0976-3147.

\footnotetext{
(c) 2021. Association for Helping Neurosurgical Sick People. All rights reserved.

This is an open access article published by Thieme under the terms of the Creative Commons Attribution-NonDerivative-NonCommercial-License, permitting copying and reproduction so long as the original work is given appropriate credit. Contents may not be used for commercial purposes, or adapted, remixed, transformed or built upon. (https://creativecommons.org/ licenses/by-nc-nd/4.0/)

Thieme Medical and Scientific Publishers Pvt. Ltd., A-12, 2nd Floor, Sector 2, Noida-201301 UP, India
} 


\section{Introduction}

In the modern era, the concept of minimally invasive neurosurgery has become an established discipline of neurosurgery. With time, minimally invasive techniques have given the concept of "minimal surgical trauma with maximum surgical efficiency." This has led to flourishing of the keyhole approach in contemporary neurosurgical practice. The keyhole approach does not necessarily mean a hole-sized craniotomy; however, the size of craniotomy can be varied according to the underlying pathology. This signifies that minimal exposure is not the primary objective of keyhole approach rather it is maximum surgical excision with minimum exploration of the surgical site which is the real philosophy behind the keyhole concept. Further, the introduction of endoscope in keyhole approach has brought down the size of craniotomy further due to its high degree of maneuverability, panoramic view, and better illumination of the surgical field, conceding new heights to the keyhole approach. Studies have shown the advantages of keyhole approach over conventional open surgery by offering a shorter hospital stay, lesser incidence of cerebrospinal fluid (CSF) leak, infection, postoperative neurologic deterioration, and seizures with better aesthetic outcome without compromising the extent of tumor resection and functional outcome. Keyhole approach has rapidly established itself as a standard of care in dealing with pathologies such as intraventricular lesions, deep seated glioma (insular glioma), and many more. ${ }^{1-3}$ Subsequently, to add one more success in the series of keyhole surgery, epidermoid is a pathology which can be an ideal lesion to be dealt exclusively with an endoscopic keyhole approach because of its inherent factors such as benign nature, well-capsulated outline, avascular interior, easy suckability, extra-axial location, and a tendency of growing along the cisternal spaces. They often encircle neurovascular structures instead of displacing them. ${ }^{4-7}$ Dense adhesion and partial visualization during conventional microscopic surgery make their total surgical excision a challenging task, favoring endoscopic approach for their complete removal. The superiority of endoscopic keyhole craniotomy in term of higher degree of resection via a minicraniotomy can be well understood by its principles of optics as shown in - Fig. 1. ${ }^{8}$ The advantages of endoscope incorporation are better illumination and panoramic vision. Through this study, the authors aim to share the experience of endoscopic keyhole approach to this relatively uncommon lesion presenting at various intracranial locations.

\section{Materials and Methods}

\section{Patient Selection}

This retrospective study included patients from a tertiary care teaching institute. Histologically confirmed, consecutive intracranial epidermoids resected using a keyhole endoscopic approach between July 2015 and December 2019 by the senior author (A.K.J.) were included. Patient's demographics, clinical symptoms, preoperative neurological deficits, radiological review including pre- and postoperative magnetic resonance imaging (MRI), per-operative details, and postoperative complications were noted. Follow-up outcome of preoperative

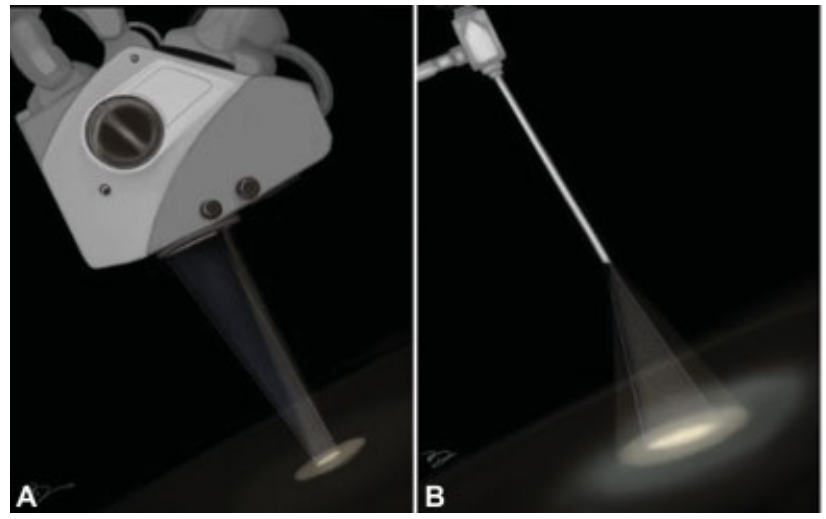

Fig. 1 Difference in surgical field view of microscope and endoscope: (A) the "funnel-shaped" view of surgical corridor of a microscope and (B) "reverse funnel-shaped" view of surgical corridor of endoscope facilitating the panoramic vision of surgical field.

symptoms (headache, facial pain, improvement in vision, hemiparesis, and cerebellar symptoms) and postoperative complications (lower cranial nerve palsy, facial palsy, pseudomeningocele, meningitis, worsening of ataxia, and CSF leak) were analyzed. The categories for extent of resection were defined as gross total resection (GTR) (intraoperative complete excision of tumor with no radiological evidence of residual tumor), near total resection (NTR) (intraoperative incomplete tumor excision with $>90 \%$ radiological excision), and subtotal resection (STR) (intraoperative incomplete tumor excision with $\leq 90 \%$ radiological excision) as reported on postoperative MRI.

\section{Operative Considerations}

Patients were positioned according to the intracranial location of tumor such as supine-lateral position with head turned for cerebellopontine (CP) angle and prepontine cistern lesions, supine position with head turned for frontotemporal and Sylvian cistern lesions, supine with head elevation for interhemispheric lesions, and prone for cisterna magna and quadrigeminal cistern lesions. Head fixation frame was used for all lesions except those present in $\mathrm{CP}$ angle and prepontine regions. Localization of individualized craniotomy site was done to ensure best suitable surgical corridor to assess the lesion. Determination of best surgical corridor was done beforehand based on location, size of tumor, surrounding structures, depth from brain surface, and tumor projection to ensure a hassle-free route to the pathological entities. All patients underwent a linear or a lazy $S$ incision measuring $\sim 4$ to $5 \mathrm{~cm}$ in length to make the predefined tailored craniotomy with the intent of optimized surgical access to the lesion. For keyhole endoscopic surgery, a 14-mm burr hole was made after dissecting the skin and subcutaneous tissue of scalp. This 14-mm hole was packed with bone dust at the end to improve cosmesis. Whenever available, creation of the initial burr hole by a high speed drill with a 4- or 5-mm cutting drill bit can allow the same procedure with much smaller bony defect. A craniotomy was made by Midas drill cutter system. The average size of craniotomy made was $\sim 2.5 \mathrm{~cm}$ (-Fig. 2). Dura mater was opened in a cruciate manner and dural flap was retracted 


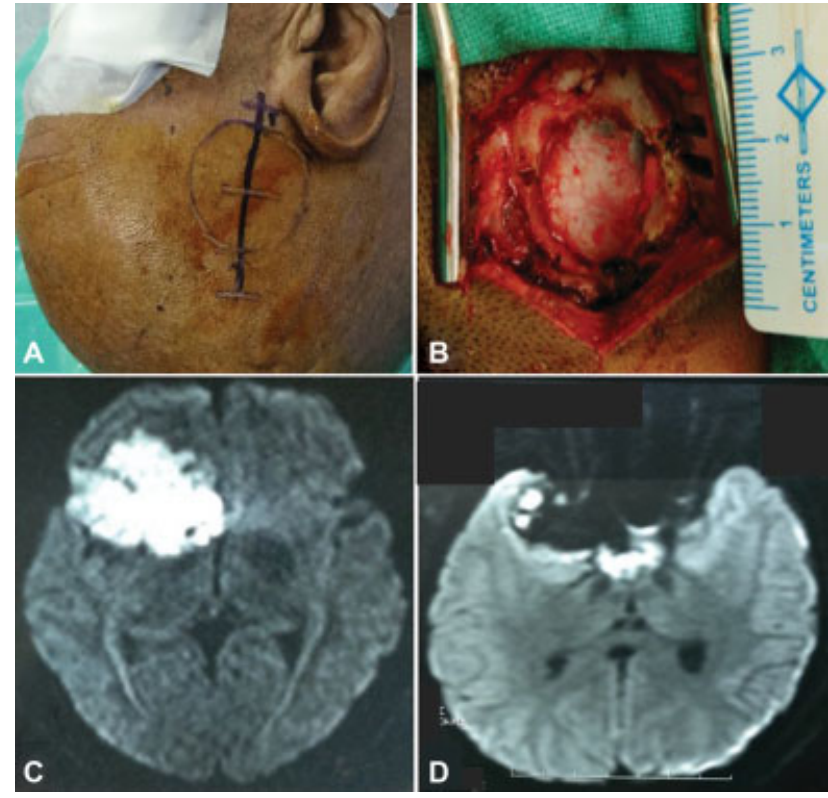

Fig. 2 Right Sylvian fissure epidermoid operated by endoscopic keyhole approach: (A) the surface marking of craniotomy and linear incision, (B) craniotomy defect measuring $\sim 2.5 \mathrm{~cm}$, (C) preoperative axial magnetic resonance (MR) image in diffusion-weighted imaging (DWI) sequence, and (D) postoperative axial MR image (DWI) showing near total excision with residual tumor left.

with the help of Silk 3.0 suture. The authors used intermittent dynamic retraction (with the help of endoscope, suction cannula, and operating instrument) to avoid crowding of instruments in the small surgical corridor. Tumor decom-

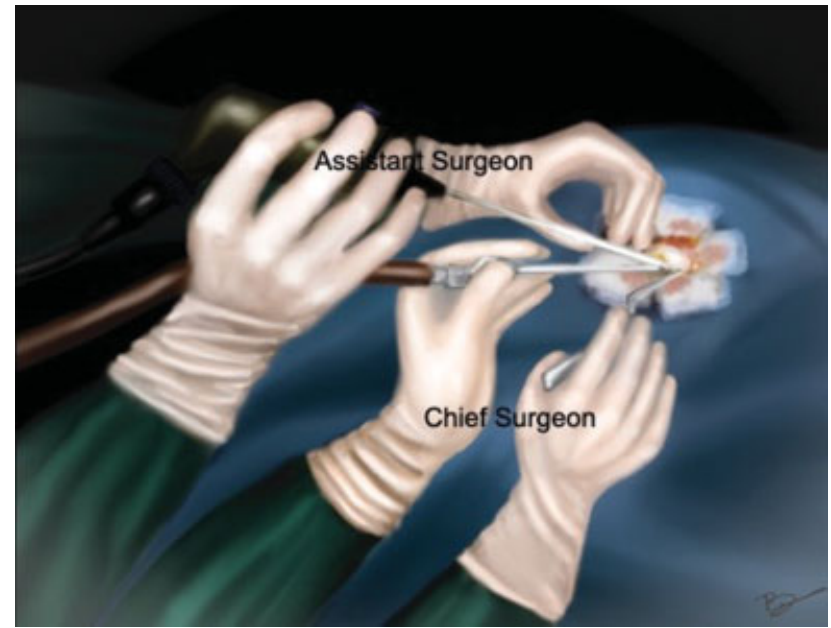

Fig. 3 Diagrammatic illustration of "two surgeons four-hands technique": assistant holds the endoscope with both hands, while surgeon holds the suction with left hand and forceps with the right hand.

pression was started using 0-degree endoscope and 30degree endoscope was introduced in the later phase of surgery to visualize the hidden areas and corners. At first, internal decompression of tumor was done followed by dissection of tumor capsule. "Two surgeons four-hands technique" was used by our team instead of an endoscope holder (-Fig. 3). As per this technique, the assistant holds the endoscope with both hands and the operating surgeon uses the operating instruments (dissector, scissor, bipolar forceps, etc., as shown in -Fig. 4) in the right hand and

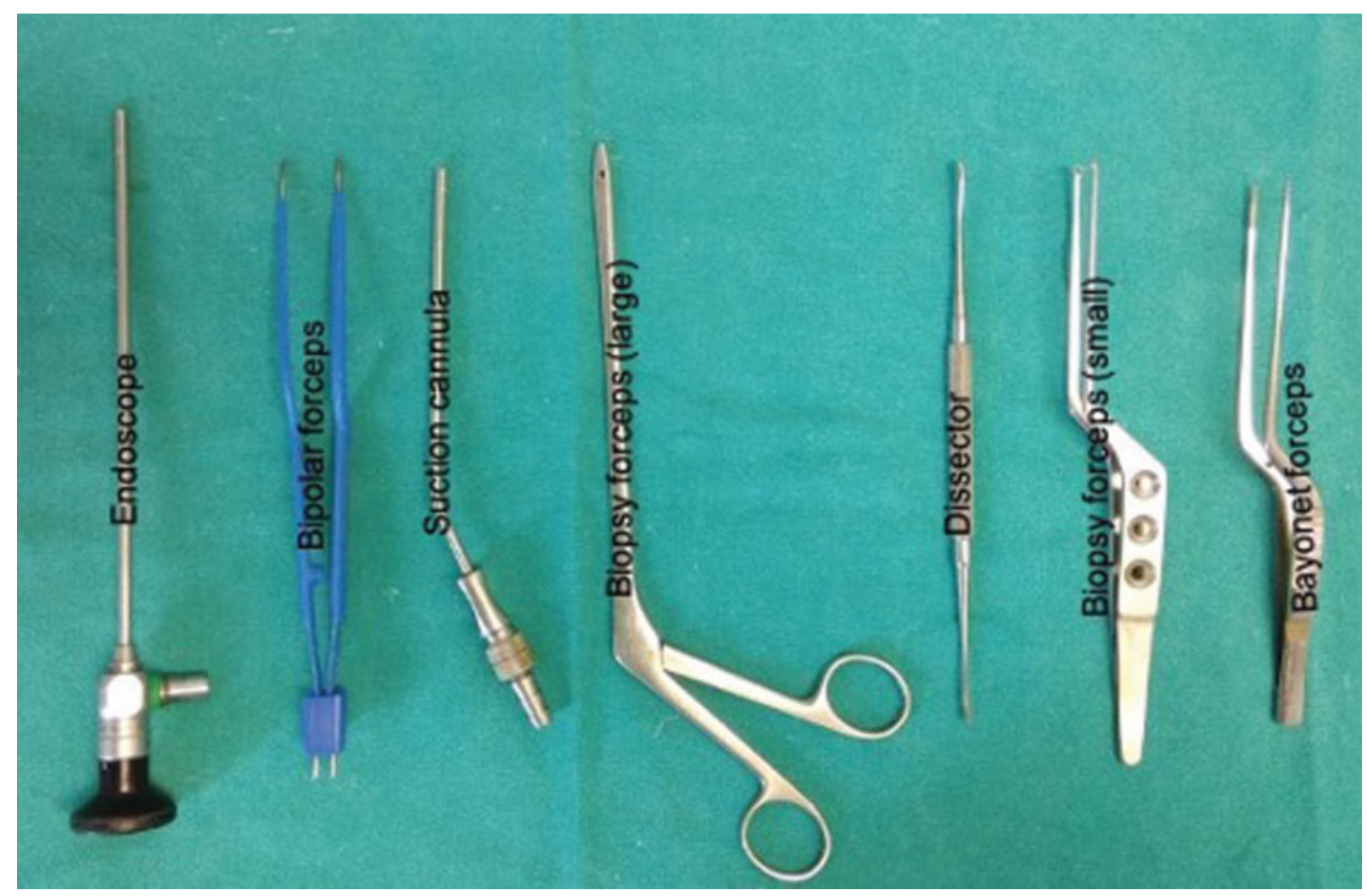

Fig. 4 Instruments frequently used in endoscopic keyhole approach. 
suction in the left hand as illustrated in - Fig. 3. This facilitates the surgeon to use intermittent dynamic retraction on the brain instead of a fixed one. This techniques not only helped us in depth perception but also contributed to the minimization of thermal injury to neurovascular structures from a constant heating.

\section{Statistical Analysis}

Patients' data were analyzed using SPSS software version 23 (Statistical Package for Social Sciences, IBM, Chicago, United States).

\section{Results}

\section{Patient Characteristic}

Total number of patients included were 26, out of which 12 were females. The mean age of our study was 30.5 years ranging from 16 to 54 years. Location wise, 19 cases were found in infratentorial compartment and 7 cases in supratentorial compartment. The most common location was found to be $\mathrm{CP}$ angle cistern (16 cases), followed by interhemispheric cistern (3 cases), prepontine cistern (2 cases), quadrigeminal cistern ( 2 cases), Sylvian fissure (1 case), frontotemporal (1 case). and cisterna magna (1 case) (-Table 1).

The most common presenting clinical symptom was headache (13 cases) followed by hearing loss ( 9 cases). Other symptoms noticed were trigeminal neuralgic pain, visual deterioration, seizure, facial hypoesthesia, cerebellar ataxia, tinnitus, and vomiting (-Fig. 5). Out of 18 cases of $\mathrm{CP}$ angle and prepontine cisterns, six patients had preoperative facial nerve involvement. The distribution of these six patients was as per the House and Brackmann (HB) grade: grade II $(n=3)$, grade III $(n=2)$, and grade IV $(n=1)$, respectively. The mean duration of
Table 1 Demographics, including age, gender, location, and mean size of tumor

\begin{tabular}{|c|c|c|}
\hline \multicolumn{2}{|l|}{ Variable } & Value \\
\hline \multicolumn{2}{|l|}{ Mean age } & $\begin{array}{l}30.5 \text { y } \\
\text { (range: 16-54) }\end{array}$ \\
\hline \multirow[t]{2}{*}{ Gender } & Male & 14 \\
\hline & Female & 12 \\
\hline \multirow[t]{7}{*}{ Location } & $\begin{array}{l}\text { Cerebellopontine } \\
\text { angle cistern }\end{array}$ & 16 \\
\hline & Interhemispheric cistern & 3 \\
\hline & Prepontine cistern & 2 \\
\hline & Quadrigeminal cistern & 2 \\
\hline & Sylvian fissure & 1 \\
\hline & Frontotemporal & 1 \\
\hline & Cisterna magna & \\
\hline \multicolumn{2}{|c|}{ Mean tumor size } & $\begin{array}{l}4.3 \mathrm{~cm} \\
\text { (range: } 2.7-6 \mathrm{~cm} \text { ) }\end{array}$ \\
\hline
\end{tabular}

symptoms was 17 months (range: 2 months-7 years). The mean tumor diameter was $4.3 \mathrm{~cm}$ (range: $2.7-6.0 \mathrm{~cm}$ ).

\section{Surgical Outcome}

Lesions were approached at multiple intracranial sites through keyhole endoscopic approach (-Figs. 6, 7, 8). Out of 26 patients, GTR was obtained in 19 cases (73.1\%), NTR was obtained in 5 cases (19.2\%), and STR was achieved in 2 cases (7.7\%) (-Table 2). Results also indicate that prepontine cistern, quadrigeminal cistern, and CP angle cistern were most difficult locations to achieve GTR. Only 50\% cases of quadrigeminal cisterns underwent GTR, while in CP angle cistern lesions, it increased up to $69 \%$. Both patients of

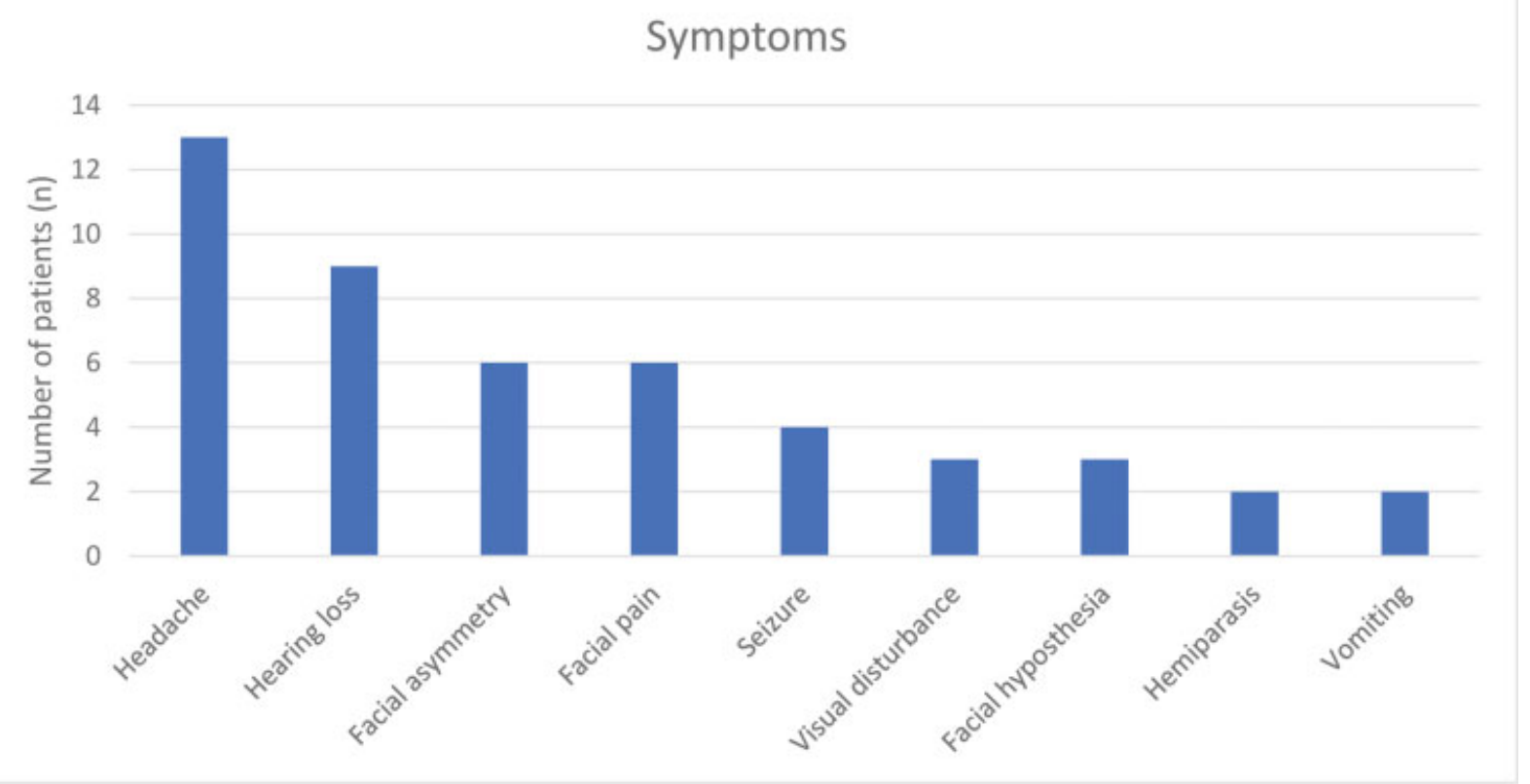

Fig. 5 Major symptoms of patients with their frequency. 

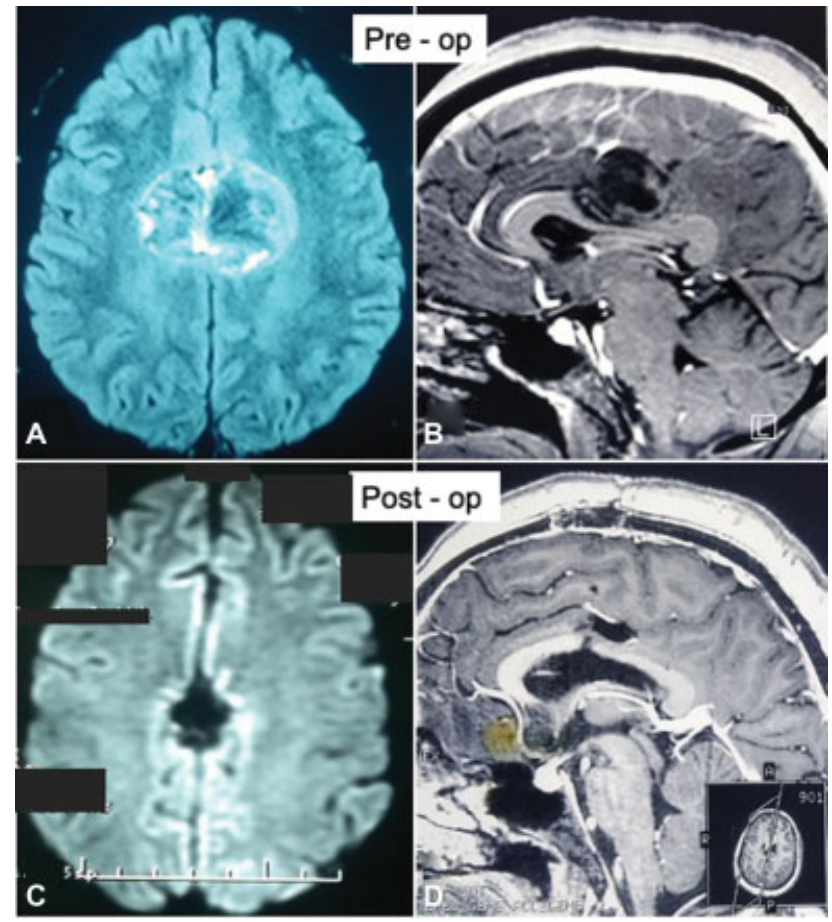

Fig. 6 Preoperative magnetic resonance (MR) imaging of a patient with interhemispheric epidermoid: (A) diffusion-weighted axial image showing the lesion with focal diffusion restriction and (B) postcontrast T1weighted coronal image showing hypointense lesion without contrast enhancement causing mass effect over corpus callosum. Postoperative MR imaging of the same patient: (C, D) diffusion-weighted axial and T1 postcontrast images showing the complete excision of lesion.
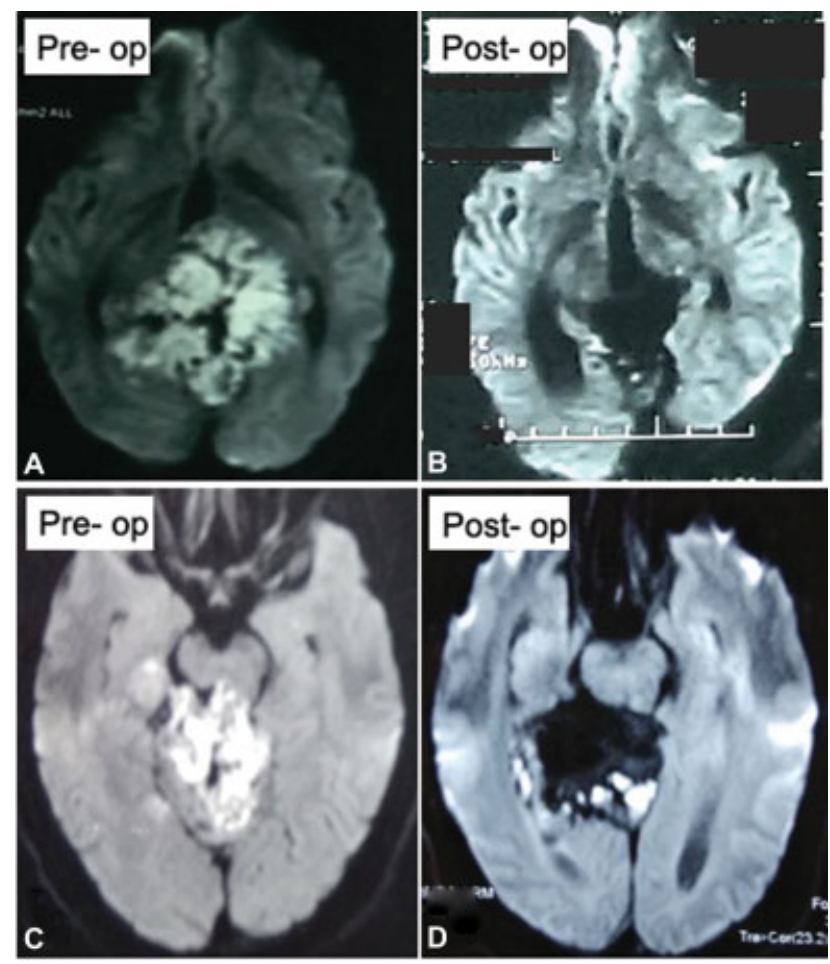

Fig. 7 (A) Preoperative and (B) postoperative magnetic resonance (MR) images (diffusion-weighted imaging [DWI]) of large quadrigeminal cistern epidermoid with complete excision, (C) preoperative and (D) postoperative MR image (DWI) of another patient of quadrigeminal cistern epidermoid with subtotal excision.
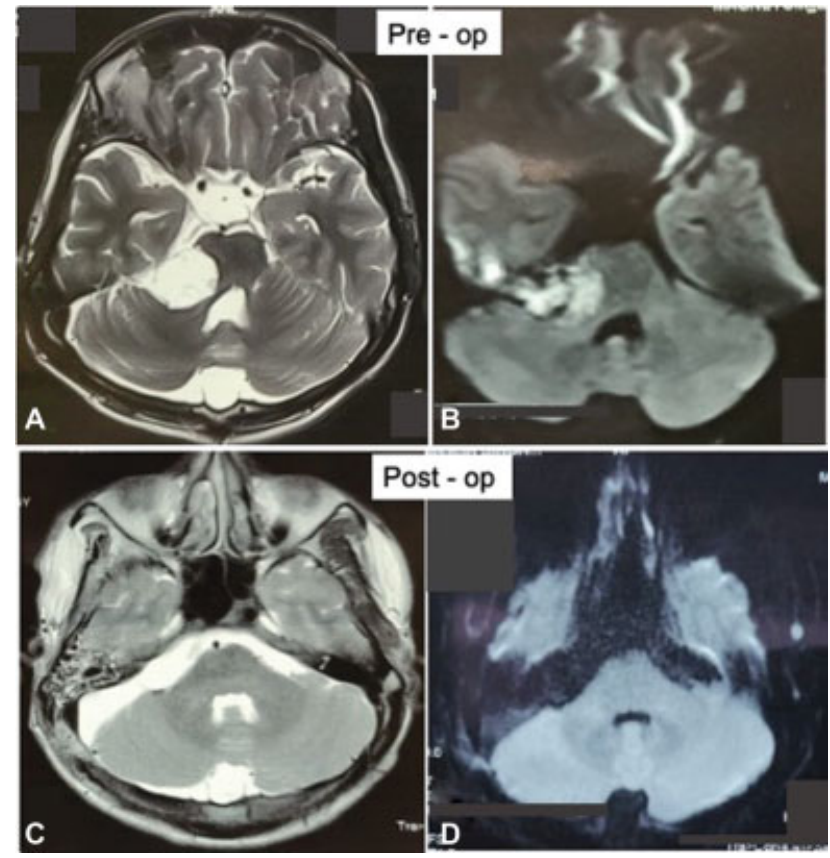

Fig. 8 Preoperative magnetic resonance (MR) imaging of a patient with cerebellopontine (CP) angle epidermoid: (A) T2-weighted axial image showing the hyperintense mass lesion extending from $C P$ angle cistern toward basal cisterns with mass effect over brain stem and (B) diffusion-weighted imaging (DWI) sequence showing diffusion restriction of mass. Postoperative MR imaging of the same patient: (C) T2-weighted axial images and (D) DWI showing complete removal of tumor.

Table 2 Outcomes of patients

\begin{tabular}{|l|l|}
\hline \multicolumn{2}{|l|}{ Radiological outcome (extent of excision in \%) } \\
\hline Gross total resection & $N=19(73.1 \%)$ \\
\hline Near total resection & $N=5(19.2 \%)$ \\
\hline Subtotal resection & $N=2(7.7 \%)$ \\
\hline Clinical outcome (symptoms improved in \% of patients) \\
\hline Headache & $N=9 / 13(66.7 \%)$ \\
\hline Trigeminal neuralgic pain & $N=5 / 6(83 \%)$ \\
\hline Lower cranial nerve palsy & $N=4 / 5(80 \%)$ \\
\hline Hemiparesis & $N=2 / 2(100 \%)$ \\
\hline Facial palsy & $N=5 / 9(56 \%)$ \\
\hline Cerebellar symptoms & $N=2 / 3(67 \%)$ \\
\hline Visual symptoms & $N=2 / 3(67 \%)$ \\
\hline
\end{tabular}

prepontine cistern epidermoid (100\%) underwent NTR. In NTR, the surgeon was compelled to leave a piece of tumor along with adherent capsule due to entanglement and dense attachment of the capsule with cranial nerves, vessels, or brain stem. Both the STRs belonged to the $\mathrm{CP}$ angle cistern category. It was due to the residual tumor remaining in hidden areas which was not visualized intraoperatively. In $\mathrm{CP}$ angle and prepontine cistern cases, seventh to eighth complex was demonstrated in all cases and anatomical 
Table 3 Comparison of the pre- and postoperative grades of the facial weakness for patient of cerebellopontine angle and prepontine locations $(N=18)$

\begin{tabular}{|l|l|l|}
\hline House-Brachmann grade & $\begin{array}{l}\text { Preoperative } \\
\text { patients }\end{array}$ & $\begin{array}{l}\text { Postoperative } \\
\text { patient }\end{array}$ \\
\hline Grade I & 12 & 9 \\
\hline Grade II & 2 & 1 \\
\hline Grade III & 3 & 3 \\
\hline Grade IV & 1 & 4 \\
\hline Grade V & 0 & 1 \\
\hline Grade VI & 0 & 0 \\
\hline
\end{tabular}

Note: Three patients develop new-onset facial paresis, while two get worsen.

preservation of the facial nerve was achieved in all cases. No intraoperative complication such as excessive brain bulge while dural opening, damage to adjacent brain parenchyma, or vascular injury occurred.

\section{Postoperative Complications}

Majority of the complications were associated with subsets of $\mathrm{CP}$ angle and prepontine cistern epidermoids. Most concerned complication encountered was facial nerve paresis which occurred in five (19.2\%) cases. There were three (11.5\%) cases of new onset of facial paresis (one each of HB grade III, grade IV, and grade V), while in two (7.7\%) patients, it presented in the form of worsening of preoperative facial paresis (one patient deteriorated to grade IV from grade II, and another grade IV from grade III). In four cases, there was no change in the grade of facial paresis (comparison of preand postoperative grades of facial weakness is shown in -Table 3). Other noticeable complications were lower cranial nerves palsy $(n=5,19.2 \%)$, transient facial hypoesthesia ( $n=4,15.4 \%)$, pseudomeningocele $(n=3,11.5 \%)$, meningitis $(n=3,11.5 \%)$, CSF leak $(n=2,7.7 \%)$, worsening of ataxia $(n=2,7.7 \%)$, and transient sixth nerve palsy $(n=2$, 7.7\%) (-Table 4). Two patients with pseudomeningocele required CSF diversion surgery in the form of shunt surgery and one patient was managed with lumber drain insertion. There was no incidence of operative site hematoma or pinrelated complications. There was mortality of one patient in $\mathrm{CP}$ angle epidermoid case due to bacterial meningitis.

\section{Follow-up}

The mean follow-up of our study is 32.8 months (range: 4-56 months). Out of 26 patients, 1 patient died and 2 patients were lost to follow-up. There was improvement in trigeminal neuralgic pain in $83 \%$ ( 5 out of 6 ) of patients, headache in $69.2 \%$ ( 9 out of 13 ) of patients, visual symptoms in $67 \%$ ( 2 out of 3 ) of patients, cerebellar symptoms in $67 \%$ (2 out of 3 ) of patients, and hemiparesis in $100 \%$ (2 out of 2 ) of patients. Improvement in postoperative complications, namely, facial paresis was found in 56\% of patients ( 5 out of 9 ) and lower cranial nerve palsy in $80 \%$ of patients ( 4 out of 5 ) ( - Table 2 ). No patient of GTR had shown any evidence of recurrence and
Table 4 Postoperative complications

\begin{tabular}{|l|l|}
\hline Complications & Number $(\boldsymbol{n})$ \\
\hline Facial nerve palsy & $19.2 \%(n=5)$ \\
\hline Lower cranial nerves palsy & $19.2 \%(n=5)$ \\
\hline Transient facial hypoesthesia & $15.4 \%(n=4)$ \\
\hline Pseudomeningocele & $11.5 \%(n=3)$ \\
\hline CSF leak & $7.7 \%(n=2)$ \\
\hline Worsening of ataxia & $7.7 \%(n=2)$ \\
\hline Transient sixth nerve palsy & $7.7 \%(n=2)$ \\
\hline Meningitis & $11.5 \%(n=3)$ \\
\hline
\end{tabular}

Abbreviation: CSF, cerebrospinal fluid.

no patient required resurgery in cases of subtotal or near total excision till the last follow-up.

\section{Discussion}

Epidermoid cysts are the congenital lesions resulting due to entrapment of surface ectoderm inside the neuroectoderm during neurulation. They are relatively uncommon intracranial lesions accounting for $\sim 1 \%$ of all intracranial tumors. ${ }^{5,9,10}$ They are very slow growing lesions presenting mostly between 20 and 40 years age group with a male predominance. Our study showed mean age of 30.5 years and male dominance (59.3\%). The most common location is CP angle cistern epidermoid which was also observed in our study. Studies have shown that there is no universal pattern of the presentation of epidermoid patients and it is variable according to its location. ${ }^{11-14}$ Our series had shown the most common presenting symptom as headache. Other common symptoms were unilateral hearing loss followed by trigeminal neuralgic pain attributing to highest number of epidermoids located in $\mathrm{CP}$ angle cistern in our series. The cranial nerve dysfunction occurs either due to direct compression or obliteration of vascular supply. Hyperactive dysfunction such as trigeminal neuralgia and hemifacial spasm are due to direct compression or local irritation because of cholesterol leakage through the capsule at root entry zone., ${ }^{4,15-18}$ The size of tumor encountered in our series was quite large with average maximum tumor diameter of $4.3 \mathrm{~cm}$ with mean duration of symptoms was 17 months which varies from months to years in the literature. ${ }^{7,18}$

However, epidermoids tend to grow without causing much symptoms until they reach a significant size, favoring the conventional large size craniotomy for their complete excision by single or staged surgery. ${ }^{19-21}$ However, with the evolution of preoperative diagnostic imaging, intraoperative illumination, and special microneurosurgical instruments, there has been tremendous development in understanding the nature of pathology, their accurate site, topographical relationship, and advanced neurosurgical techniques. The same has resulted into selection of safest and optimal corridor for the lesions using the smallest possible surgical exposure, that is, the keyhole craniotomy. The authors 


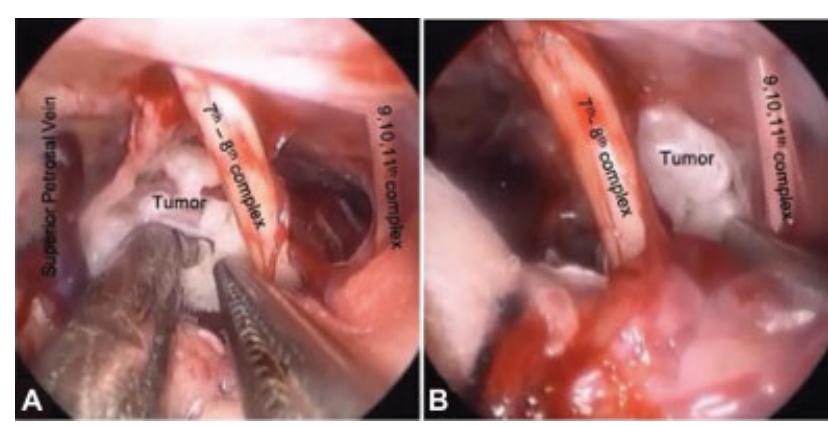

Fig. 9 Various intraoperative corridors in cerebellopontine angle epidermoid (A) between superior petrosal vein and seventh-eighth nerve complex and (B) between seventh-eighth nerve complex and lower cranial nerve complex.

believe that though it is true for all pathological entities, it is specially proving to be a boon for pathologies such as epidermoids because of their inherent mild behavior during surgery and existing natural surgical corridor due to their tendency to expand in the subarachnoid spaces. Our series supports this hypothesis and demonstrates for the first time the feasibility of achieving excellent results without increase in postoperative complications by using keyhole techniques for epidermoid. Studies have shown that the major difficulty encountered during removal of epidermoid cyst is the complete excision of capsule. The strategy to improve the capsule excision was to approach it from multiple angles during the last part of surgery. Endoscope favors the comparatively small size of craniotomy for large-sized lesions along with well-illuminated crystal-clear panoramic view of the surgical field which is not limited by craniotomy edge and without much brain retraction. The endoscope also allows the usage of different passages from different angles to separate the capsule from important neurovascular structures under direct vision, aiding in maximal capsule excision (-Fig. 9). The authors used at least three corridors in the CP angle cistern and two corridors in the prepontine cistern epidermoids during tumor excision. Preservation of the bridging vein is also possible through more than one corridor for tumor excision in the interhemispheric location. We could achieve gross total and near total removal of tumor in $92.3 \%$ of patients and subtotal removal in $7.7 \%$ of patients using keyhole approach which proved to be better than conventional microscopic method. ${ }^{7,10,22}$ Studies have shown that the best chance to remove the epidermoid completely is during the very first surgery, but it cannot be achieved every time as the epidermoid insinuates and encircles vital neurovascular structures instead of displacing them. Although we did not specially estimate the duration of these surgeries, in our experience, one procedure take approximately 1 and half hour to 2 hours which is significantly shorter than a pure microscopic or a combined microendoscopic approach.

As per our experience, considering all intracranial epidermoids, the location of the tumor was the primary factor determining the extent of resection. When we statistically analyzed the correlation between extent of resection with variables (age, gender, location, and size), the $p$-value was not found significant for any variable ( - Table 5 ). This finding
Table 5 Statistical correlation of various factors for extent of excision

\begin{tabular}{|c|c|c|c|c|c|}
\hline \multicolumn{2}{|l|}{ Variables } & \multicolumn{3}{|c|}{ Extent of excision (n) } & \multirow{2}{*}{$\begin{array}{l}\text { p-Value } \\
\text { (Fisher's } \\
\text { exact } \\
\text { test) }\end{array}$} \\
\hline & & $\begin{array}{l}\text { Gross } \\
\text { total }\end{array}$ & $\begin{array}{l}\text { Near } \\
\text { total }\end{array}$ & $\begin{array}{l}\text { Sub } \\
\text { total }\end{array}$ & \\
\hline \multirow[t]{2}{*}{ Age } & $\leq 40$ & 15 & 4 & 2 & \multirow[t]{2}{*}{0.714} \\
\hline & $>40$ & 3 & 2 & 0 & \\
\hline \multirow[t]{2}{*}{ Sex } & Male & 10 & 5 & 1 & \multirow[t]{2}{*}{0.437} \\
\hline & Female & 8 & 1 & 1 & \\
\hline \multirow[t]{2}{*}{ Location } & Supratentorial & 6 & 3 & 0 & \multirow[t]{2}{*}{0.547} \\
\hline & Infratentorial & 12 & 3 & 2 & \\
\hline \multirow{2}{*}{$\begin{array}{l}\text { Size } \\
(\mathrm{cm})\end{array}$} & $\geq 4$ & 13 & 4 & 1 & \multirow[t]{2}{*}{0.822} \\
\hline & $<4$ & 5 & 2 & 1 & \\
\hline
\end{tabular}

can be attributed to a small sample size and analysis on a larger sample size is required to substantiate the findings. Intraoperatively $\mathrm{CP}$ angle cisterns, prepontine cisterns, and quadrigeminal cisterns were the locations where the authors faced real challenge for GTR but were still able to achieve high rate of functional preservation of structures with a permissible rate of complications.

Seventh nerve paresis was the most concerned complication including the new-onset as well as worsening of preexisting facial paresis seen in $19.2 \%$ of patients, followed by lower cranial nerve palsy also in $19.2 \%$ of patients. However, most of these improved during the follow-up. ${ }^{5,6,9,15}$ The incidence of aseptic meningitis in our series was $7.7 \%$ against the value of 0 to $40 \%$ mentioned in the literature. ${ }^{4,7,20}$ This is caused by the spillage of cholesterol crystals and breakdown products into the CSF and is usually more prevalent after incomplete resection. ${ }^{23}$ No preoperative shunt surgery was required in the patient having hydrocephalus. The author believe that hydrocephalus is a reversible condition if treated timely and properly, although some studies have recommended preoperative shunt surgery for patients presenting with hydrocephalus., ${ }^{5,24}$ There were $11.5 \%$ incidences of pseudomeningocele in our series which was managed by postoperative lumbar drain in one case and postoperative shunt surgery in two cases. The analysis of preoperative complaints showed that the facial pain was most responsive to surgical treatment followed by the headache. The cerebellar symptoms and visual symptoms also improved but in lesser number of patients.

To avoid the complications, one has to master harmoniously orchestrating the micromovement of instruments, gentle resection under the direct vision, avoiding thermal injury from light source, and meticulous primary dural closure. Thermal injury in endoscopic is a proven and genuine concern. ${ }^{25}$ We attempt to minimize this by the "two surgeons four-hands technique" instead of using the endoscope holder. Holding of the endoscope by an assistant facilitates the dynamic to and fro movement of endoscope which avoids constant heating at a particular place and also 
gives the much needed depth perception of surgical field. The other ways to prevent thermal injury are keeping the operating room temperature below 20 degrees and intermittent irrigation of the endoscope tip as well as surgical field with normal saline at room temperature. It is preferred to use of thin, long shaft instruments during endoscopic procedures. This avoids reaching the area of interest without much struggle and with minimal "sword fighting" of the instruments. We generally use the standard microsurgical instruments such as bayonetted forceps (-Fig. 4). We use longest available instruments for deeper portions of these tumors. Therefore, even the standard instruments, which often are very comfortable for the operating surgeon, can be used in these surgeries. Although desirable, specialized instruments, to our mind, is rarely major limitation for the performance of the surgery, once sufficient experience is gained with other simpler neuroendoscopic procedures. At the same time, precise movement of instruments in a narrow corridor, manipulation of instruments with respect to each other, comprehensive understanding of intraoperative anatomical orientation, and control of bleeding are making its learning curve steep.

The significant advantages of pure endoscopic over pure microscopic or endoscopic-assisted approach are like uncomplicated patient positioning, small bony/dura exposure, practically no need for applying brain retractors, better delineation of neurovascular structures and blind corners, actual confirmation of the extent of capsule resection, and finally reduction of operation time. Studies by Singh et al and Peng et al have showed that pure endoscopy has been employed in the resection of CP angle epidermoids. They have mentioned different advantages over pure microscopy or hybrid approaches in terms of less tissue damage, easy access of nearby cistern through same craniotomy to allow quick CSF drainage and brain relaxation, lesser duration of hospital stay, and better extent of excision with comparable cranial nerve morbidity profile. ${ }^{26,27}$ One should start the practice of this approach with simple endoscopic microvascular decompression, followed by relatively small and avascular tumors such as epidermoids and cystic vestibular schwannomas. However, the case selection is very crucial because soft, suckable, low-grade or benign tumors with relatively less vascularity and extra-axial location are favorable factors for keyhole approach. The authors also want to emphasize that once the surgeon has acquired enough experience, the size of lesion does not matter in the endoscopic keyhole approach, provided the patient selection and the preoperative planning is perfect. ${ }^{28}$

\section{Conclusion}

Keyhole surgery is gaining popularity in the contemporary neurosurgery and use of the endoscope adds distinct advantages. The surgical strategy of this discipline is not focused on limited craniotomy but on minimal brain exposure and retraction. It is an art to execute the narrow but precise surgical corridor through a keyhole to excise the targeted lesion. With this series, the authors have demonstrated that the endoscopic excision of epidermoid is feasible and a viable alternative to conventional microscopic excision with good oncologic and functional outcomes. Out of 26 cases, we achieved GTR and NTR in $92.3 \%$ of cases with high rate of functional preservation, while STR in $7.7 \%$ cases. The successful outcome depends on the factors such as patient selection for approach, meticulous preoperative planning, customized craniotomy site for each patient, and ability to use the angled lens shaft to visualize the hidden areas.

Conflict of Interest

None declared.

\section{References}

1 Barber SM, Rangel-Castilla L, Baskin D. Neuroendoscopic resection of intraventricular tumors: a systematic outcomes analysis. Minim Invasive Surg 2013;2013:898753

2 Hoshide R, Faulkner H, Teo M, Teo C. Keyhole retrosigmoid approach for large vestibular schwannomas: strategies to improve outcomes. Neurosurg Focus 2018;44(03):E2

3 Sughrue ME, Othman J, Mills SA, Bonney PA, Maurer AJ, Teo C. Keyhole transsylvian resection of infiltrative insular gliomas: technique and anatomic results. Turk Neurosurg 2016;26(04): 475-483

4 Kobata H, Kondo A, Iwasaki K. Cerebellopontine angle epidermoids presenting with cranial nerve hyperactive dysfunction: pathogenesis and long-term surgical results in 30 patients. Neurosurgery 2002;50(02):276-285, discussion 285-286

5 Mohanty A, Venkatrama SK, Rao BR, Chandramouli BA, Jayakumar PN, Das BS. Experience with cerebellopontine angle epidermoids. Neurosurgery 1997;40(01):24-29, discussion 29-30

6 Samii M, Tatagiba M, Piquer J, Carvalho GA. Surgical treatment of epidermoid cysts of the cerebellopontine angle. J Neurosurg 1996;84(01):14-19

7 Schiefer TK, Link MJ. Epidermoids of the cerebellopontine angle: a 20-year experience. Surg Neurol 2008;70(06):584-590, discussion 590

8 Mori K. Keyhole concept in cerebral aneurysm clipping and tumor removal by the supraciliary lateral supraorbital approach. Asian J Neurosurg 2014;9(01):14-20

9 Nagasawa D, Yew A, Safaee M, et al. Clinical characteristics and diagnostic imaging of epidermoid tumors. J Clin Neurosci 2011;18 (09):1158-1162

10 Gopalakrishnan CV, Ansari KA, Nair S, Menon G. Long term outcome in surgically treated posterior fossa epidermoids. Clin Neurol Neurosurg 2014;117:93-99

11 Barker FG II, Jannetta PJ, Bissonette DJ, Larkins MV, Jho HD. The long-term outcome of microvascular decompression for trigeminal neuralgia. N Engl J Med 1996;334(17):1077-1083

12 Nagata S, Matsushima T, Fujii K, Fukui M, Kuromatsu C. Hemifacial spasm due to tumor, aneurysm, or arteriovenous malformation. Surg Neurol 1992;38(03):204-209

13 Nomura T, Ikezaki K, Matsushima T, Fukui M. Trigeminal neuralgia: differentiation between intracranial mass lesions and ordinary vascular compression as causative lesions. Neurosurg Rev 1994;17(01):51-57

14 Obrador S, Lopez-Zafra JJ. Clinical features of the epidermoids of the basal cisterns of the brain. J Neurol Neurosurg Psychiatry 1969;32(05):450-454

15 Hasegawa M, Nouri M, Nagahisa S, et al. Cerebellopontine angle epidermoid cysts: clinical presentations and surgical outcome. Neurosurg Rev 2016;39(02):259-266, discussion 266-267

16 Meng L, Yuguang L, Feng L, Wandong S, Shugan Z, Chengyuan W. Cerebellopontine angle epidermoids presenting with trigeminal neuralgia. J Clin Neurosci 2005;12(07):784-786 
17 Singh AK, Jain VK, Chhabra DK, Hongo K, Kobayashi S. Hemifacial spasm and cerebellopontine angle epidermoid: case report and review. Neurol Res 1994;16(04):321-323

18 Nair P, Sahu RN, Kumar R, Behari S, Nair AP, Srivastava AK. Large epidermoids of the quadrigeminal cistern: an experience of 15 consecutive cases and review of literature. Acta Neurochir (Wien) 2012;154(08):1391-1398

19 Aboud E, Abolfotoh M, Pravdenkova S, Gokoglu A, Gokden M, AlMefty O. Giant intracranial epidermoids: is total removal feasible? J Neurosurg 2015;122(04):743-756

20 Czernicki T, Kunert P, Nowak A, Wojciechowski J, Marchel A. Epidermoid cysts of the cerebellopontine angle: clinical features and treatment outcomes. Neurol Neurochir Pol 2016;50(02): 75-82

21 de Oliveira RS, Maia WS, Santos MV, Camara RLB. Combined pre- and subtemporal transtentorial approach for epidermoid cysts of the cerebellopontine angle. Childs Nerv Syst 2012;28(12):2137-2142

22 Salazar J, Vaquero J, Saucedo G, Bravo G. Posterior fossa epidermoid cysts. Acta Neurochir (Wien) 1987;85(1-2):34-39
23 Safavi-Abbasi S, Di Rocco F, Bambakidis N, et al. Has management of epidermoid tumors of the cerebellopontine angle improved? A surgical synopsis of the past and present. Skull Base 2008;18(02): 85-98

24 deSouza CE, deSouza $\mathrm{R}$, da Costa $\mathrm{S}$, et al. Cerebellopontine angle epidermoid cysts: a report on 30 cases. J Neurol Neurosurg Psychiatry 1989;52(08):986-990

25 Panigrahi M, Gupta B, Reddy R. Neuroendoscopy - is it safe? Asian J Neurosurg 2017;12(01):17-21

26 Singh S, Das KK, Kumar K, et al. Cerebellopontine angle epidermoids: comparative results of microscopic and endoscopic excision using the retromastoid approach. J Neurol Surg B Skull Base 2021 (ePub ahead of print). Doi: 10.1055/s-0040-1722713

27 Peng Y, Yu L, Li Y, Fan J, Qiu M, Qi S. Pure endoscopic removal of epidermoid tumors of the cerebellopontine angle. Childs Nerv Syst 2014;30(07):1261-1267

28 Parab A, Khatri D, Singh S, et al. Endoscopic keyhole retromastoid approach in neurosurgical practice: Ant-Man's view of the neurosurgical marvel. World Neurosurg 2019;126:e982-e988 